\title{
A case of Fournier's gangrene after hydrocelectomy
}

\section{Badereddin Mohamad Al-Ali, Helmut Popper, Karl Pummer}

Department of Urology, Medical University of Graz, Graz, Austria

\section{KEY WORDS}

Fournier's gangrene $D$ hydrocelectomy

hyperbaric oxygen chamber necrotizing fasciitis

\section{ABSTRACT}

An uncommon case of Fournier's gangrene following hydrocelectomy is described. A 78-year-old male with no remarkable previous history, who underwent hydrocelectomy in another hospital, developed Fournier's gangrene 15 days later. The patient required wide aggressive surgical debridement, hyperbaric oxygen chamber and broadspectrum antibiotic coverage. Afterwards the patient was referred for plastic surgery. Fournier's gangrene is a polymicrobial infection of perineoscrotal region that manifests as a rapidly progressive necrotizing fasciitis. Fournier's gangrene following hydrocelectomy is uncommon. The morbidity and mortality in this severe complication depend on early diagnosis and aggressive surgical management.

\section{INTRODUCTION}

Due to the high mortality that is still associated with necrotizing fasciitis of the genital and perineal regions, this condition continues to be a major challenge to the medical community despite enormous advances in both antibiotic therapy and intensive medical treatment. It was originally reported by Baurienne [1] in 1764 and is named after Jean Alfred Fournier (1832-1914), a Parisian dermatologist who was the first to describe this fulminating infection of subcutaneous tissue and superficial fascia as being specific to the scrotum and penis.

In 1883 and 1884, Fournier presented five cases of a rapidly progressing gangrenous infection in five otherwise healthy young men $[2,3]$. In the following decades, further cases were reported in the literature, and different terms were used to describe this clinical entity.

Meleney, for example, described a more generalized form of the disease in 1924, denoting it as 'streptococcal gangrene' [4]. Wilson introduced the term 'necrotizing fasciitis', which is still used today [5]. Whereas the cardinal points of Fournier's description of the disease included origin in healthy young men, sudden onset of clinical signs, rapid progression to gangrene, and the absence of a definite cause, our understanding of this disease has changed considerably since then [2]. Table 1 shows the diagnostic criteria for necrotizing fasciitis according to Fisher et al. [6].

Fournier's gangrene is a polymicrobial infection of perineoscrotal region that manifests as a rapidly progressing necrotizing fasciitis. Fournier's gangrene following hydrocelectomy is uncommon. The morbidity and mortality in this severe complication depend on early diagnosis and aggressive surgical management.

An uncommon case of Fournier's gangrene following hydrocelectomy is described.

\section{CASE REPORT}

A 78-year- old male, 15 days before referral to our department had his left hydrocelectomy (Winkelmann's procedure) at another hospital. This patient was referred to our department because of scrotal pain and swelling.

Clinically, the patient had a temperature of 38 degrees $C_{1}$ peripheral pulses were palpable, CBC revealed leukocytosis $(26000$, range: 4000-10000), CRP was elevated (300, range: 0-8), ultrasound revealed and enlarged left testis with swelling and fluids in the scrotal content as well as an enlarged epididymis. Initial diagnosis of orchidoepididymitis with multiple abscesses was made. Further surgical exploration of the scrotum was done, after obtaining an informed consent from the patient.

Operative procedure consisted of left hemiscrotectomy as well as placement of suprapubic catheter. Microbiological examination revealed Actinomyces turicensis, Streptococcus viridans, and Staphylococcus. Histological examination of the excised scrotal tissue revealed necrosis, phlegmonous inflammation, and abscesses of the scrotum, as well as necrotizing fasciitis (Fig. 1). Informed consent was obtained from the patient for publishing this report.

The patient was further managed with hyperbaric oxygen chamber and parenteral administration of broad spectrum antibiotics (Imipenem $3 \mathrm{~g}$ daily and Cefotaxim daily $6 \mathrm{~g}$ as well as Metronidazol $2 \mathrm{~g}$ dialy) in an intensive care unit. Following resolution of his critical condition, the patient was referred to the department of plastic surgery for Mesh-Grafting and vacuum assisted closure and skin auto transplantation.

\section{DISCUSSION}

Fournier's gangrene begins as a local infection that is caused by bacteria inhabiting the lower gastrointestinal tract or the perineum. It occurs next to the portal of entry, which is often difficult to identify. The infection progresses to an inflammatory

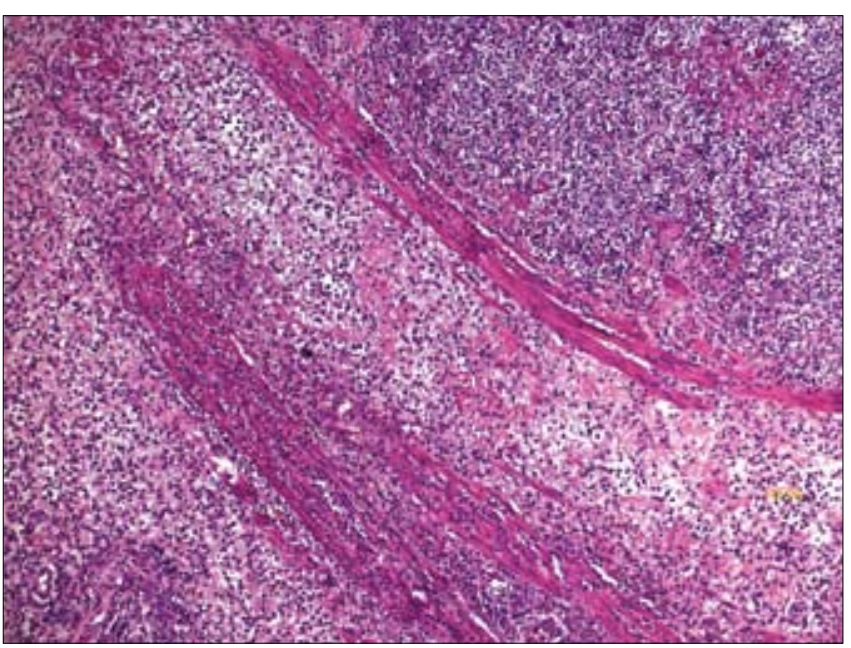

Fig. 1. Histological examination of the excised scrotal tissue revealed necrosis, phlegmonous inflammation, and abscesses of the scrotum, as well as necrotiz ing fasciitis. 
Table 1. Diagnostic criteria for necrotizing fasciitis (according to Fisher et al. [6])

Extensive fascial necrosis with involvement of the adjacent skin (histological evidence of thrombosis of the microvasculature)

\section{Severe pain ${ }^{\mathrm{a}}$}

Erythema with poorly defined margins

Marked edema extending beyond erythema

Livid discoloration of the skin with a map-like appearance involving especially the central area (zone of necrosis)

Decreased level of consciousness, disorientation

Absence of lymphadenopathy

Absence of primary muscle involvement

Failure to demonstrate clostridia in wound cultures

ance neurons are destroyed, pain diminishes

response that spreads to the fascia, with resultant obliterative endarteritis, thrombosis of the cutaneous and subcutaneous vessels, and tissue necrosis. The synergistic action of aerobic and anaerobic organisms plays a major role in the progressive course of the infection [7]. An understanding of the spread of Fournier's gangrene requires knowledge of the fascial structures of the pelvic floor and anogenital region. Colles' fascia, which is the superficial fascia of the perineum, plays an important role in this context [8]. The dartos fascia is the continuation of this layer over the scrotum and penis.

Colles' fascia is attached to the urogenital diaphragm and merges with Scarpa's fascia of the anterior abdominal wall. The spread of infection along these fascial planes was reported in Fournier's original description of a gangrene 'de la verge'. Buck's fascia surrounds the deeper structures of the penis and the periurethral region. Infection may spread from Buck's fascia to Colles' fascia and the dartos fascia especially in association with injuries.

There is general agreement in the literature about the initial treatment of patients with Fournier's gangrene. Rapid fluid resuscitation and the restoration of cardiopulmonary function have an undisputed role in the management of septic patients, who are often critically ill. Likewise, initial therapy should always include broad-spectrum antibiotics to treat the infection, which is often polymicrobial in origin. Since enteric bacteria are known to be frequently involved in the disease process, the antibiotic regimen must provide cover against these organisms. In the majority of cases, double or triple drug therapy with a combination of a thirdgeneration cephalosporin, metronidazole, and an aminoglycoside for Gram-negative aerobes and other organisms is instituted.

Antibiotics must be modified as appropriate according to culture results. The key to survival for patients with Fournier's gangrene, however, is prompt and aggressive surgical intervention. The objective of surgery is the removal of devitalized tissue in order to halt the progress of infection and eliminate the systemic effects of necrotic material, toxins, and bacteria. Surgical debridement of necrotic tissue must be repeated until a clean and healthy wound bed is present [9].

Hydrocelectomy is the gold standard technique for the treatment of hydrocele worldwide.

Standard surgical procedures for hydrocele may cause postoperative discomfort, temporary limitation of normal activities and complications, such as hematoma, infection [10].

It is estimated that 14\% of patients who undergo hydrocelectomy will develop postoperative infection [11].

Frequent complications were reported after scrotal surgery and infections (3.6\%). The potential patient and surgical risk factors considered were immune-compromised status, undergoing a bilateral procedure, or a high American Society of Anesthesiologists score [12].

Fournier's gangrene is a well-known, often fatal fasciitis of the pelvic floor following urologic infections. Predisposing factors include diabetes because of microangiopathy and polyneuropathy, alcoholism, immune-defects, and consumptive diseases [13].

According to Bönner in most cases this infection is a mixture of aerobic and anaerobic microbial agents, which result in streptococcal toxic shock-like syndrome (TSLS). We considered the recommendations and guidelines in the literature in our management, such as: wide surgical debridement; intensive care unit and hyperbaric oxygenation; broad-spectrum antibiotic coverage; and referral for plastic surgery [10].

Fortunately we succeeded in our patient management and he recovered from the above-mentioned lethal complication.

\section{REFERENCES}

1. Baurienne $\mathrm{H}$ : Sur une plaie contuse qui s'est terminee par la sphacele de la scrotum. J Med Chir Pharm 1764; 20: 251-256.

2. Fournier JA: Gangrene foudroyante de la verge. Med Pract 1883; 4: 589-597.

3. Fournier JA: Etude clinique de la gangrene foudroyante de la verge. Semaine Med 1884; 4: 69.

4. Meleney FL: Hemolytic streptococcus gangrene. Arch Surg 1924; 9: 317-364.

5. Wilson B: Necrotizing fasciitis. Am Surg 1952; 18: 416-431.

6. Fisher JR, Conway MJ, Takeshita RT, Sandoval MR: Necrotizing fasciitis. Importance of roentgenographic studies for soft tissue gas. JAMA 1979; 241: 803-806.

7. Giuliano A, Lewis F Jr, Hadley K, Blaisdell FW: Bacteriology of necrotizing fasciitis. Am J Surg 1977; 134: 52-57.

8. Smith GL, Bunker CB, Dinneen MD: Fournier's gangrene. Br J Urol 1998; 81: 347-355

9. Scott SD, Dawes RFH, et al: The practical management of Fournier's gangrene. Ann R Coll Surg Engl 1988; 70: 16-20.

10. Onol SY, Ilbey YO, Onol FF, et al: A novel pull-through technique for the surgical management of idiopathic hydrocele. J Urol 2009; 181 (3): $1201-$ 1205.

11. Khaniya $S$, Agrawal CS, Koirala R, et al: Comparison of aspiration-sclerotherapy with hydrocelectomy in the management of hydrocele: a prospective randomized study. Int J Surg 2009; 7: 392-395.

12. Swartz MA, Morgan TM, Krieger JN. Complications of scrotal surgery for benign conditions. Urology 2007: 69: 616-619.

13. Bönner $C$, Prohm $P$, Störkel S: Fournier gangrene as a rare complication after stapler hemorrhoidectomy. Case report and review of the literature. Chirurg 2001; 72: 1464-1466.

\section{Correspondence}

Badereddin Mohamad Al-Ali

Medical University of Graz

Department of Urology

7, Auenbruggerplatz

A-8036 Graz, Austria

phone: +436767615811

bader1971@gmx.at 